Please do not remove this page

RMIT

UNIVERSITY

\title{
Platelet-derived growth factor-stimulated versican synthesis but not glycosaminoglycan elongation in vascular smooth muscle is mediated via Akt phosphorylation
}

Osman, Narin; Getachew, Robel; Thach, Lyna; Wang, Haitao; Su, Xiaoying; Zheng, Wenhua; Little AM, Peter https://researchrepository.rmit.edu.au/esploro/outputs/9921859466601341/filesAndLinks?institution=61RMIT_INST\&index=null

Osman, N., Getachew, R., Thach, L., Wang, H., Su, X., Zheng, W., \& Little AM, P. (2014). Platelet-derived growth factor-stimulated versican synthesis but not glycosaminoglycan elongation in vascular smooth muscle is mediated via Akt phosphorylation. Cellular Signalling, 26(5), 912-916.

https://doi.org/10.1016/j.cellsig.2014.01.019

Document Version: Submitted Version

Published Version: https://doi.org/10.1016/j.cellsig.2014.01.019

Repository homepage: https://researchrepository.rmit.edu.au

(C) 2014 Elsevier Inc. All rights reserved.

Downloaded On 2023/04/27 00:32:17 +1000 
Thank you for downloading this document from the RMIT Research Repository.

The RMIT Research Repository is an open access database showcasing the research outputs of RMIT University researchers.

RMIT Research Repository: http://researchbank.rmit.edu.au/

\section{Citation:}

Osman, N, Getachew, R, Thach, L, Wang, H, Su, X, Zheng, W and Little AM, P 2014, 'Platelet-derived growth factor-stimulated versican synthesis but not glycosaminoglycan elongation in vascular smooth muscle is mediated via Akt phosphorylation', Cellular Signalling, vol. 26, no. 5, pp. 912-916.

See this record in the RMIT Research Repository at:

http://researchbank.rmit.edu.au/view/rmit:24894

Version: Submitted Version

Copyright Statement: (c) 2014 Elsevier Inc. All rights reserved.

Link to Published Version:

http://dx.doi.org/10.1016/j.cellsig.2014.01.019 


\title{
Platelet-Derived Growth Factor-stimulated versican synthesis but not glycosaminoglycan elongation in vascular smooth muscle is mediated via Akt phosphorylation
}

\author{
Narin Osman ${ }^{\mathrm{a}, \mathrm{b}}$, Robel Getachew ${ }^{\mathrm{a}}$, Lyna Thach ${ }^{\mathrm{a}}$, Haitao Wang ${ }^{\mathrm{c}}$, Xiaoying $\mathrm{Su}^{\mathrm{c}}$, Wenhua Zheng ${ }^{\mathrm{a}, \mathrm{c}}$ \\ and Peter. J. Little ${ }^{a, b}$
}

${ }^{a}$ Discipline of Pharmacy, School of Medical Sciences and Diabetes Complications Group, Health Innovations Research Institute, RMIT University, Bundoora, VIC 3083 Australia ${ }^{b}$ Monash University, Departments of Medicine and Immunology, Central and Eastern Clinical School, Alfred Health, Melbourne, Victoria, Australia, ${ }^{c}$ State Key Laboratory of Ophthalmology, Zhongshan Ophthalmic Center and School of Pharmaceutical Sciences, Sun Yat-sen University, Guangzhou, China.

Running title: Akt signalling and proteoglycan synthesis

\author{
Address correspondence to: \\ Dr Narin Osman \\ Discipline of Pharmacy, School of Medical Sciences, \\ RMIT University, Melbourne, Victoria 3083 Australia \\ Tel: $\quad+61399256686$ \\ Email: $\quad$ narin.osman@ rmit.edu.au
}




\begin{abstract}
Proteoglycans are associated with the initiation of atherosclerosis due to their binding of apolipoproteins on lipid particles leading to retention in the vessel wall. The signalling pathways through which growth factors regulate the synthesis and structure of proteoglycans are potential therapeutic targets. Platelet-derived growth factor (PDGF) is present in atherosclerotic plaques and activates phosphorylation of the serine/threonine kinase Akt. We have investigated the role of Akt in the signalling pathways for proteoglycan core protein expression and elongation of glycosaminoglycan chains on proteoglycans secreted by human vascular smooth muscle cells. The pharmacological inhibitor of Akt phosphorylation, SN30978, blocked PDGF stimulated phosphorylation of Akt. SN30978 caused concentration dependent inhibition of PDGF stimulated radiosulfate incorporation into secreted proteoglycans and the response was blocked by the PDGF receptor antagonists Ki11502 and imatinib. Analysis of the size of the biglycan molecules by SDS-PAGE showed that PDGF increased the apparent size of biglycan but this effect on glycosaminoglycan chain elongation was blocked by Ki11502 but not by SN30978. PDGF also stimulated total protein core protein synthesis assessed as ${ }^{35} \mathrm{~S}$-methionine/cysteine incorporation and specifically the expression of versican mRNA. Both of these responses were blocked by SN30978. This data shows that PDGF-stimulated proteoglycan core protein synthesis but not glycosaminoglycan chain elongation is mediated via Akt phosphorylation. These data identify potential pathways for the development of agents which can pharmacologically regulate individual components of the synthesis of proteoglycans.
\end{abstract}

Keywords: Platelet-derived growth factor, proteoglycans, GAG hyperelongation, Akt, atherosclerosis 


\section{Introduction}

The underlying pathology of most cardiovascular disease (CVD) is atherosclerosis [1, 2]. Atherosclerosis is characterized by a pre-inflammatory stage involving the retention of atherogenic lipoproteins by modified proteoglycans (PGs) in the vessel wall[3, 4]. The later chronic inflammatory stage involves the accumulation of immunogenic products and the formation of atherosclerotic plaques[5] [6]. A human pathology study showed unequivocally that deposition of extracellular lipid (LDL) in association with the proteoglycan biglycan, precedes the inflammatory response $[7,8]$.

Proteoglycans are composite protein carbohydrate molecules expressed throughout the body [9]. The glycosaminoglycan (GAG) chains on PGs are heavily sulfated and show avid binding for many cationic molecules including apolipoproteins [10]. The synthesis of proteoglycan core proteins and GAG chains are distinct independently regulated biochemical processes [11]. Hormones and growth factors including transforming growth factor (TGF)- $\beta[12]$, plateletderived growth factor (PDGF)[13], endothelin[14] and thrombin[15] stimulate vascular smooth muscle cells (VSMCs) resulting in increased core protein expression and an increase in the size of the GAG chains on secreted PGs[12, 13, 15, 16]. Several GAG synthesising enzymes CSGalNAcT2 and C4ST-1 were recently demonstrated to be upregulated in an in vivo mouse model of atherosclerosis [17]. The signalling pathways for proteoglycan synthesis are potential targets for the development of therapeutic agents which prevent proteoglycan-dependent diseases including atherosclerosis [18]. We have demonstrated the potential of this approach in a mouse model of atherosclerosis using an inhibitor of GAG elongation [14, 19].

The serine/threonine kinase, Akt, also known as protein kinase B, is growth factor responsive and is associated with cell survival in response to insulin-like growth factor-1 [20]. Aberrant Akt 
signalling is associated with numerous cancers [21]. We recently observed that the proatherogenic growth factor TGF- $\beta$ mediates its effects on proteoglycan synthesis in VSMCs via phosphorylation of the signalling intermediate Akt[6]. Other pro-atherosclerotic growth factors such as PDGF can be even more potent activators of Akt phosphorylation. PDGF and TGF- $\beta$ have distinct signalling pathways but with some overlap that can include Akt. We have recently demonstrated that TGF- $\beta$ stimulates Akt phosphorylation in human VSMCs and that this pathway is involved in TGF- $\beta$ stimulated proteoglycan core protein expression but not chondroitin sulfate/dermatan sulfate (CS/DS) GAG elongation in these cells[6]. Further, we have previously demonstrated that the effect of PDGF on proteoglycan synthesis involves the activation of phosphatidylinositol 3-kinase (PI3K) [19] an upstream effector of Akt phosphorylation.

In the current work we have investigated the role of Akt phosphorylation in PDGF-stimulated proteoglycan core protein expression and GAG chain hyperelongation including assessment of the expression of the relevant genes being versican and chondroitin-4sulfotransferase (C4ST-1), respectively in human vascular smooth muscle cells (VSMC). We find that PDGF is a highly efficacious mediator of Akt phosphorylation and that pharmacological inhibition of Akt phosphorylation is associated with inhibition of proteoglycan core protein synthesis for versican but not GAG elongation or the expression of C4ST-1. These data indicate the common role of phosphoAkt derived from either PDGF or TGF- $\beta$ stimulation in the activation of proteoglycan core protein synthesis in these cells. These data identify potential pathways for the development of agents which can pharmacologically regulate individual components of the synthesis of proteoglycans. 
Materials and Methods.

\section{Materials}

Dulbecco's Modified Eagle Medium (DMEM) was from Invitrogen Corporation, USA. Foetal bovine serum (FBS) and penicillin-streptomycin-fungizone solution, PDGF-BB and other standard reagents were purchased from Sigma-Aldrich Australia. Sulfur-35 $\mathrm{Na}_{2} \mathrm{SO}_{4}\left(\left[{ }^{35} \mathrm{~S}\right]-\right.$ sulfate) and Trans ${ }^{35}$ S-label $\left({ }^{35} \mathrm{~S}\right.$-Met/Cys) were from MP Biomedicals, USA. Cetyl pyridinium chloride (CPC) was from Unilab Chemicals and Pharmaceuticals, Mumbai, India. Rainbow $\left[{ }^{14} \mathrm{C}\right]$ methylated protein molecular weight markers were from Amersham Pharmacia Biotech, USA.

\section{Cell Culture}

Human VSMCs from the saphenous vein were isolated and characterised as previously described [22]. The Human Ethics Committee at the Alfred Hospital (Melbourne, Australia) approved this procedure.

\section{Quantitation of radiolabel incorporation into proteoglycans}

Quiescent human VSMCs in 24 well plates were treated in $0.5 \mathrm{ml} 5 \mathrm{mM}$ glucose DMEM, 0.1\% FBS, $0.1 \%$ DMSO with and without inhibitors as detailed in Results section and exposed to ${ }^{35} \mathrm{~S}_{-} \mathrm{SO}_{4}(50 \mu \mathrm{Ci} / \mathrm{ml})$ in the presence of PDGF $(50 \mathrm{ng} / \mathrm{ml})$ for 24 hours. Secreted proteoglycans

were harvested and ${ }^{35} \mathrm{~S}_{-} \mathrm{SO}_{4}$ incorporation into proteoglycans was quantitated using the CPC precipitation assay $[12,23,24]$.

\section{SDS-PAGE analysis of proteoglycan size}

Proteoglycans were sized by SDS-PAGE as described previously [24]. In all instances three measurements were performed from three separate experiments with a representative shown. SDS-PAGE gels show dotted white line as an estimate of the mid-line of PG or GAG band size.

\section{Western blots}


Total cell lysates were resolved on 10\% SDS-PAGE and transferred onto PVDF. Membranes were blocked with 5\% skim milk powder, incubated with antibodies as described previously [19]. Primary antibodies used in this study were anti-phosphoAkt (phosphoThr308) antibody and anti-GAPDH antibody (Cell Signaling Technology, MA, USA). Secondary antibodies were HRP-anti-species specific IgG and were followed by ECL detection (Amersham). Blots from three experiments were quantified by densitometry using QuantityOne software (BioRad).

\section{Reverse transcription PCR}

RNA from cultured VSMC cells was extracted using Trizol (Invitrogen, Carlsbad, CA, USA) following the manufacturer's protocol and reverse transcription was performed using Allin-one First-strand cDNA synthesis kit (GeneCopoeia, USA) and Quantitect Reverse Transcription Kit (Qiagen). Versican primer sequences primer sequences were: forward 5'GCCGCCTTCCAAGGCCAAGA -3', reverse 5'- GCCCCTCACCGGTGGGCTTT -3'; chondroitin-4-sulfotransferase (C4ST-1) primers were: forward 5'- GGCCCTGCGCAAAG -3', reverse 5'- GGGTGTGTGGGTCGATGAG -3'. Primers for 18s were purchased from Qiagen (Hs_RRN18S_1_SG QuantiTect Primer Assay, Qiagen). The PCR products were examined on agarose gels with ethidium bromide staining.

\section{Statistical analyses}

Data was analysed for statistical significance using a 1-way analysis of variance (ANOVA) or a Student's paired t-test as stated. Results were considered statistically significant at $\mathrm{P}<0.05$ as stated. Normalisation of data was performed in some investigations to adjust for control variations between individual experiments with data shown as mean \pm SEM. 


\section{Results}

We have previously reported that PDGF stimulates the phosphorylation of Akt in human VSMCs and that this response is blocked by the specific inhibitor, SN30978 [6]. In the present studies we have confirmed this result by showing that PDGF stimulated and SN30978 $(2 \mu \mathrm{M})$ totally inhibited the effect of PDGF on Akt phosphorylation in these cells (Fig. 1). This data characterizes SN30978 as an inhibitor of the Akt pathway in these cells. (Fig. 1). We further characterized the response as being dependent upon the PDGF receptor and its tyrosine kinase activity by utilizing two PDGF receptor antagonists, Ki11502 and imatinib which we have previously characterized as PDGF receptor inhibitors in these cells [14, 19]. PDGF stimulated phosphorylation of Akt was totally blocked by Ki11502 (300 nM). In preliminary experiments with imatinib we used the concentration $(1 \mathrm{uM})$ which we have previously shown to block (>95\%) phosphorylation of the autophosphorylation site Tyr 857 of the human PDGF receptor $\beta$ [19]. Interestingly, imatinib $(1 \mu \mathrm{M})$ did not completely block the PDGF stimulation of Akt phosphorylation but it was completely blocked by a ten-fold higher concentration (Fig. 1). These data confirmed that PDGF treatment of human VSMCs leads to PDGF receptor activation followed by downstream phosphorylation of Akt.

We next assessed the ability of the Akt inhibitor, SN30978, to inhibit PDGF stimulated $\left[{ }^{35}\right.$ S]sulfate incorporation into secreted proteoglycans from human VSMCs (Figure 2). VSMCs were grown to confluency, serum-deprived for $24 \mathrm{~h}$ then stimulated with PDGF and treated with pharmacological inhibitors and secreted proteoglycans were quantitated by the CPC precipitation method which is specific for the determination of proteoglycans [25, 26]. VSMCs were treated for $24 \mathrm{~h}$ with PDGF $(50 \mathrm{ng} / \mathrm{ml})$ in the presence of SN30978 $(30-3000 \mathrm{nM})$ and Ki11502 (300 nM). PDGF stimulated an approximately two-fold increase in $\left[{ }^{35} \mathrm{~S}\right]$-sulfate incorporation 
which is consistent with earlier reports [19]. The response to PDGF was blocked in a concentration-dependent manner by SN30978 with a half maximally effective inhibitory concentration of approximately $500 \mathrm{nM}$ and a maximum response which represented total inhibition of the effect of PDGF with no impact on the basal level of $\left[{ }^{35} \mathrm{~S}\right]$-sulfate into proteoglycans (Fig. 2). The PDGF inhibitor, Ki11502, also totally blocked the stimulatory effect of PDGF on $\left[{ }^{35} \mathrm{~S}\right]$-sulfate incorporation without an appreciable effect on the basal rate of incorporation (Fig. 2).

The major mechanisms through which increased $\left[{ }^{35} \mathrm{~S}\right]$-sulfate incorporation can arise are from increased proteoglycan core protein expression (and hence more GAG initiation sites) and/or an elongation of the GAG chains on the proteoglycan core proteins [11] an effect which usually occurs on all of the family of secreted CS/DS proteoglycans. The changes in average size of the proteoglycans can be assessed by SDS-PAGE because the core protein has a defined molecular weight and any change in size must result from changes in the size of the GAG chains [11]. The predominant small leucine-rich CS/DS proteoglycan synthesized by these cells is biglycan [27]. PDGF stimulated an increase in the size of biglycan synthesized and secreted by these cells (Fig. 3A, compare lanes 1 and 2) but the GAG elongation effect was not blocked by SN30978 (Fig. 3A, lanes 2-7). As expected, Ki11502 (300 nM) inhibited PDGF-stimulated GAG elongation (Fig. 3A, lane 2 versus 8). To confirm whether Akt is a signalling intermediate in PDGF-mediated GAG synthesis we measured the gene expression level of GAG synthesizing enzyme chondroitin-4-sulfotransferase (C4ST-1) in VSMCs (Fig. 3B, 3C). PDGF caused an increase in C4ST-1 mRNA expression up to a maximal 2 - 3-fold increase at $6 \mathrm{~h}$ (Fig. 3). Pretreatment with Akt inhibitor SN30978 had no effect on the PDGF-mediated increase in C4ST-1 
gene expression at $6 \mathrm{~h}$ (Fig. 3C). Together the data clearly demonstrates that Akt is not involved in PDGF-stimulated GAG hyperelongation in VSMCs.

As SN30978 did not block PDGF-stimulated GAG elongation, we assessed if the blockade of PDGF-stimulated $\left[{ }^{35} \mathrm{~S}\right]$-sulfate incorporation was due to inhibition of proteoglycan core protein expression. We used ${ }^{35} \mathrm{~S}$-met/cys labeling and CPC precipitation to quantitate proteoglycan core protein expression. PDGF caused a small statistically significant increase in total core protein expression and this was blocked in a concentration dependent manner by SN30978 (30 - 3000 nM) and was totally blocked by Ki11502 (300 nM) (Fig. 4).

We wanted to examine which specific core protein expression was stimulated by PDGF. In these human VSMCs we can detect a small increase in biglycan mRNA in response to TGF- $\beta$ but in accord with the results of others not to PDGF $[6,28]$. Although the amount of versican produced by human VSMC is very small relative to primate VSMCs, Wight and colleagues have demonstrated a marked increase in versican mRNA in response to PDGF [28]. We thus treated human VSMCs with PDGF for $0-24 \mathrm{~h}$ and measured versican mRNA expression levels (Figure 5A). Peak levels of expression were seen at $24 \mathrm{~h}$ of PDGF exposure. In subsequent experiments VSMCs were treated with PDGF in the presence of SN30978 and Ki11502 and the level of versican mRNA was measured (Fig. 5B). PDGF stimulated a small increase in mRNA for versican and the response was blocked by SN30978 and LY294002 (Fig. 5B) an antagonist of PI3 kinase upstream of Akt. These data show that PDGF stimulates Akt phosphorylation in human VSMCs and that downstream signalling leads to increased proteoglycan core protein expression but not GAG elongation. 


\section{Discussion}

In this paper we show that PDGF is a potent activator of Akt phosphorylation in human VSMCs and that PDGF-stimulated proteoglycan core protein synthesis for the CS/DS proteoglycan versican is Akt dependent. The stimulation of CS/DS GAG elongation by PDGF does not involve Akt phosphorylation. This is similar to the lack of involvement of Akt in proteoglycan GAG elongation recently reported for TGF- $\beta$ [6]. These data reveal both the similarities and some of the differences in the signalling pathways that regulate proteoglycan synthesis in vascular smooth muscle. In the current work we have identified a growth factor signalling intermediate, Akt, which regulates core protein expression but not GAG elongation.

Of the possible pathways for generating an agent for the prevention of lipid binding and retention in the vessel wall and thus atherosclerosis, we are searching for an agent which is a specific inhibitor of the GAG elongation response, termed hyperelongation [4, 29]. As proteoglycans are ubiquitously expressed and play vital structural roles in many tissues it is unlikely that inhibiting core protein expression would provide efficacious, specific and safe therapeutic agents. In contrast, many vasoactive compounds present in atherosclerotic vessels stimulate elongation of GAG chains and to the extent that longer GAG chains leads to enhanced binding to lipoproteins in vitro that in itself may represent a therapeutic target $[10,11,30]$. We have shown that the tyrosine kinase inhibitor, imatinib prevents GAG elongation effects and enhanced binding in vitro and it also reduces lipid deposition in the vessel wall of high fat fed $\mathrm{ApoE}^{-/-}$mice[14, 19]. Imatinib inhibits both the GAG elongation effect of PDGF as well as the increased expression of proteoglycan core proteins which is not surprising as we show in the 
current work that imatinib inhibits PDGF-stimulated Akt phosphorylation which is a key pathway in proteoglycan core protein expression.

One question is how Akt might be involved in the stimulation of proteoglycan, specifically versican, core protein expression in these cells. Thus far we are able to make several conclusions about the signalling pathways controlling the synthesis of proteoglycans and specifically the increased expression of proteoglycan core proteins and GAG elongation. These two parameters of proteoglycan synthesis appear to have different signalling pathways - GAG elongation involves Mitogen Activated Protein (MAP) kinase, specifically Erk and possibly p38 phosphorylation[19, 31], whereas the pathways for the increased expression of core proteins involve intermediates most closely associated with cell cycle progression such as Akt[6]. Growth factor action on tyrosine kinase cell surface receptors leads to activation of PI3K and subsequently phosphorylation of Akt as reported here and earlier. Considering examples for cancer cells, increased levels of Akt result in negative regulation and a decrease in the level of the transcription factor FoxO and the cell cycle dependent factor $\mathrm{p} 27^{\mathrm{kip} 1}[6,32]$. In the context of vascular biology growth factor mediated proliferation involves decreased levels of p27 ${ }^{\text {kip1 }}$ [33]. The isoflavone and anti-proliferative agent genistein mediates its inhibitory activity by blocking the decrease in $\mathrm{p} 27^{\mathrm{kip} 1}$ levels[33]. Genistein also blocks core protein expression but not PDGFmediated GAG elongation in VSMCs[28]. We can speculate that the downstream events associated with growth factor mediated Akt phosphorylation involve FoxO and $\mathrm{p} 27^{\mathrm{kip} 1}$.

In conclusion, proteoglycans are molecules with key structural and functional roles in tissues and studies are demonstrating the plasticity of this quantitatively small but qualitatively critical component of the extracellular matrix. Earlier concepts around the static and inert nature of the extracellular matrix are being supplanted by studies showing that signalling pathways controlling 
the structure of proteoglycans are as complex and as interesting as those regulating the cell cycle. The serine/threonine kinase Akt is known to be involved in glucose metabolism, cell proliferation, apoptosis, transcription and cell migration but we have shown that it is also involved in the pathways leading to the synthesis of extracellular matrix. Further research will lead to an enhanced understanding of the currently unknown processes that control the synthesis of CS/DS GAG chains on proteoglycans and may yield agents which target diseases in which proteoglycans are implicated [34, 35].

\section{Acknowledgements.}

This work was supported by grants from the National Health \& Medical Research Council of Australia Project Grant (\#1022800) and a National Heart Foundation Grant-ion-aid (G09M4385). This work was also supported by National Natural Science Fund of China (No.

30711120565; No. 30970935; No.31371088); Funding from Chinese State Administration of Foreign Experts Affairs and Administration of Foreign Experts Affairs of Guangdong Province; Funding from Guangdong Science and Technology Department (No. 2009B060700008, No. 2011B050200005). 


\section{Figure Legends}

Figure 1. An Akt1/2 inhibitor completely blocks PDGF stimulated phosphorylation of Akt in human VSMCs.

Cells were untreated (-) or pre-treated for 30 min with the Akt1/2 inhibitor SN30978 (SN, $2 \mu \mathrm{M})$ or PDGF inhibitors Ki11502 (Ki, $300 \mathrm{nM})$ and imatinib (Imat, 1 and $10 \mathrm{uM}$ ) and then stimulated with PDGF (50 ng/ml) for $1 \mathrm{~h}$. Cell lysates were processed and probed for phosphoAkt (pAkt) and GAPDH as described.

Figure 2. Role of Akt in PDGF-stimulated proteoglycan synthesis in human VSMCs. VSMCs were pre-treated for 30 min with SN30978 (0 - $3000 \mathrm{nM})$ or Ki11502 (300 nM) and then stimulated with PDGF $(50 \mathrm{ng} / \mathrm{ml})$ for $24 \mathrm{~h}$ in the presence of $\left[{ }^{35} \mathrm{~S}\right]$-sulfate. Histogram values are expressed as percentage of untreated control value, \#\# $\mathrm{P}<0.01$ vs control, $* * \mathrm{P}<0.01$ vs agonist for 3 independent experiments.

Figure 3. Role of Akt in PDGF-mediated GAG synthesis in human VSMCs.

(A) VSMCs were pre-treated for 30 min with SN30978 (0 - 3000 nM) or Ki11502 (300 nM) and then stimulated with PDGF $(50 \mathrm{ng} / \mathrm{ml})$ for $24 \mathrm{~h}$ in the presence of $\left[{ }^{35} \mathrm{~S}\right]$-sulfate. SDS-PAGE analysis of $\left[{ }^{35} \mathrm{~S}\right]$-sulfate incorporated samples. (B) C4ST-1 mRNA expression in human VSMCs after $0,4,6,8$ and $10 \mathrm{~h}$ of PDGF $(50 \mathrm{ng} / \mathrm{ml})$ treatment expressed as fold change over untreated control level. Results are shown as the mid-range value of duplicate experiments. (C) C4ST-1 mRNA expression in VSMCs untreated (-) or pre-treated with SN30978 (SN) for 30 mins followed by PDGF treatment for $6 \mathrm{~h}$ expressed as fold change over untreated control level. 
Figure 4. Role of Akt in PDGF-stimulated proteoglycan core protein synthesis in human VSMCs.

VSMCs were pre-treated for 30 min with SN30978 $(0-3000 \mathrm{nM})$ or Ki11502 $(300 \mathrm{nM})$ and then stimulated with PDGF $(50 \mathrm{ng} / \mathrm{ml})$ for $24 \mathrm{~h}$ in the presence of $\left[{ }^{35} \mathrm{~S}\right]-\mathrm{Met} / \mathrm{Cys} 24 \mathrm{~h}$. Histogram values are expressed as percentage of untreated control value, \#\# $\mathrm{P}<0.01$ vs control, ** $\mathrm{P}<0.01$ vs agonist.

Figure 5. Pharmacology of the signalling pathway mediating PDGF stimulated versican mRNA expression in human VSMCs.

(A) Confluent serum-deprived human VSMCs were treated with PDGF $(50 \mathrm{ng} / \mathrm{mL})$ for the time points indicated and the expression of versican mRNA was determined by RT-PCR and expressed as fold change over untreated control value. $\beta$-Actin expression was used as a loading control. (B) VSMCs were treated with PDGF (50 ng/mL) for $24 \mathrm{~h}$ after 30 min pre-treatment with SN30978 (an Akt inhibitor) or LY294002 (an inhibitor of PI3K). \# P<0.05 vs control, * $\mathrm{P}<0.05$ vs agonist. 


\section{Figure 1}

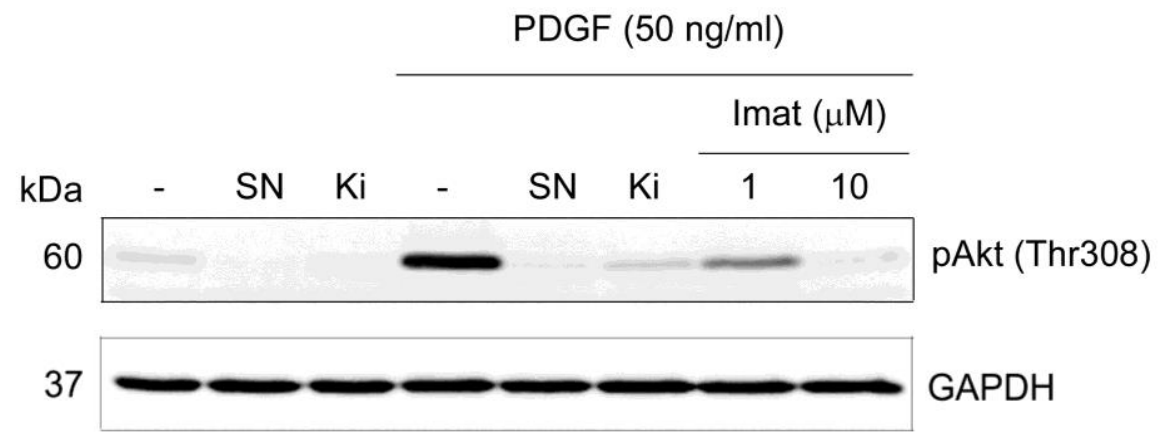


Figure 2

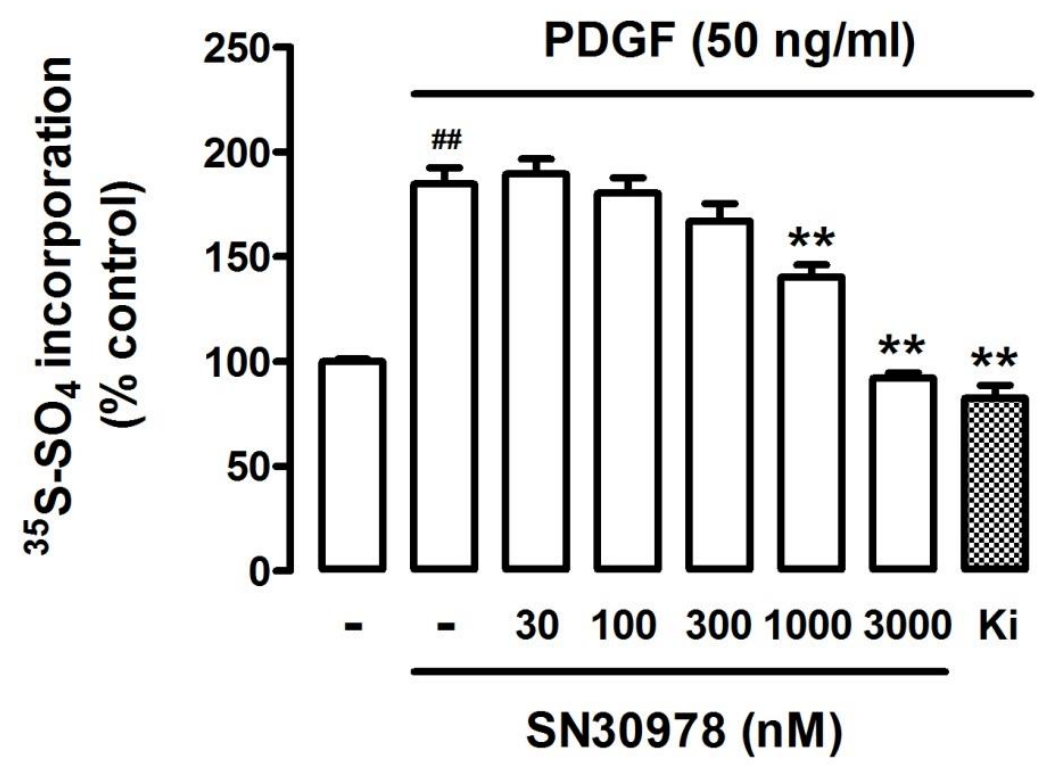


Figure 3
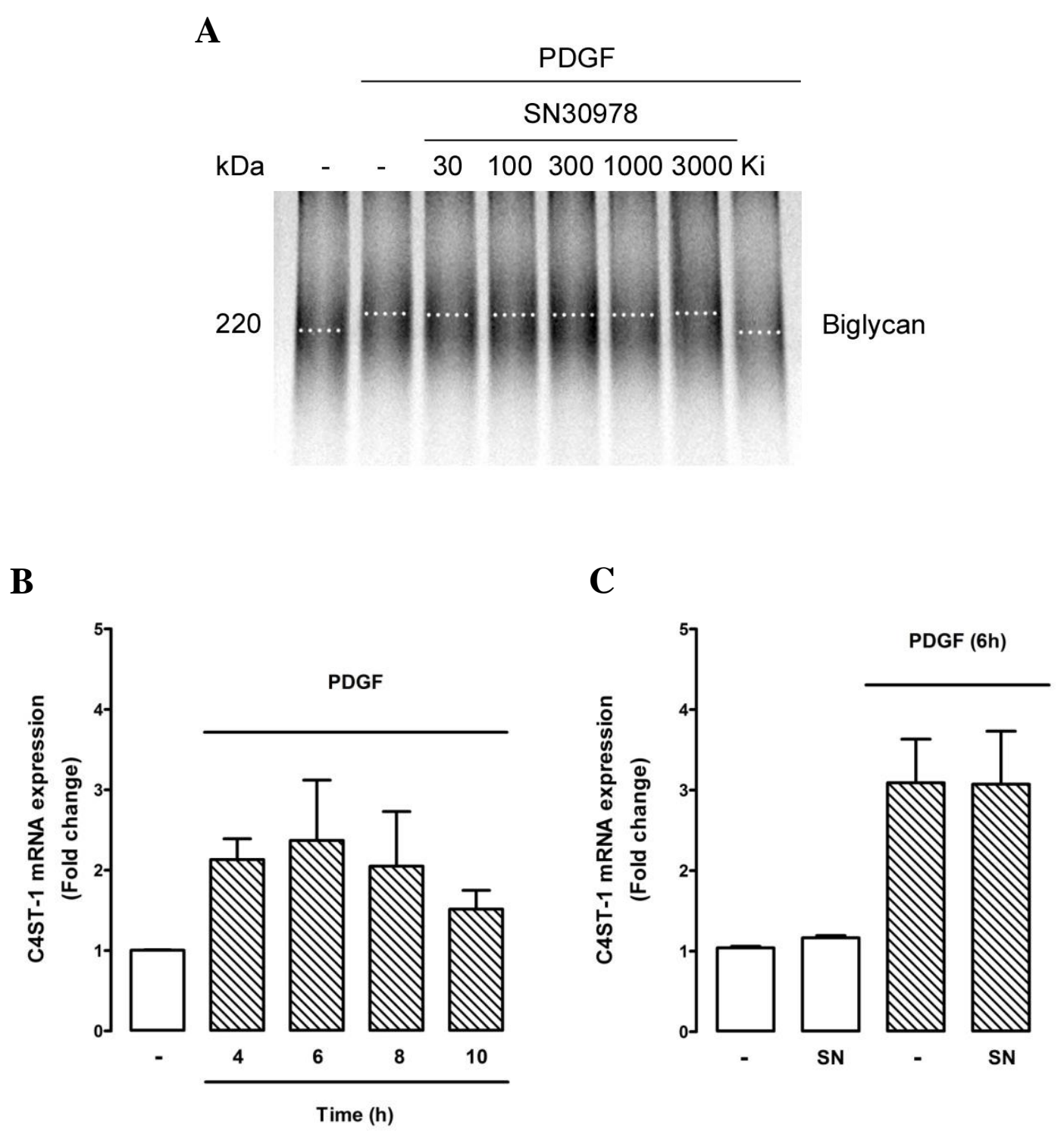
Figure 4

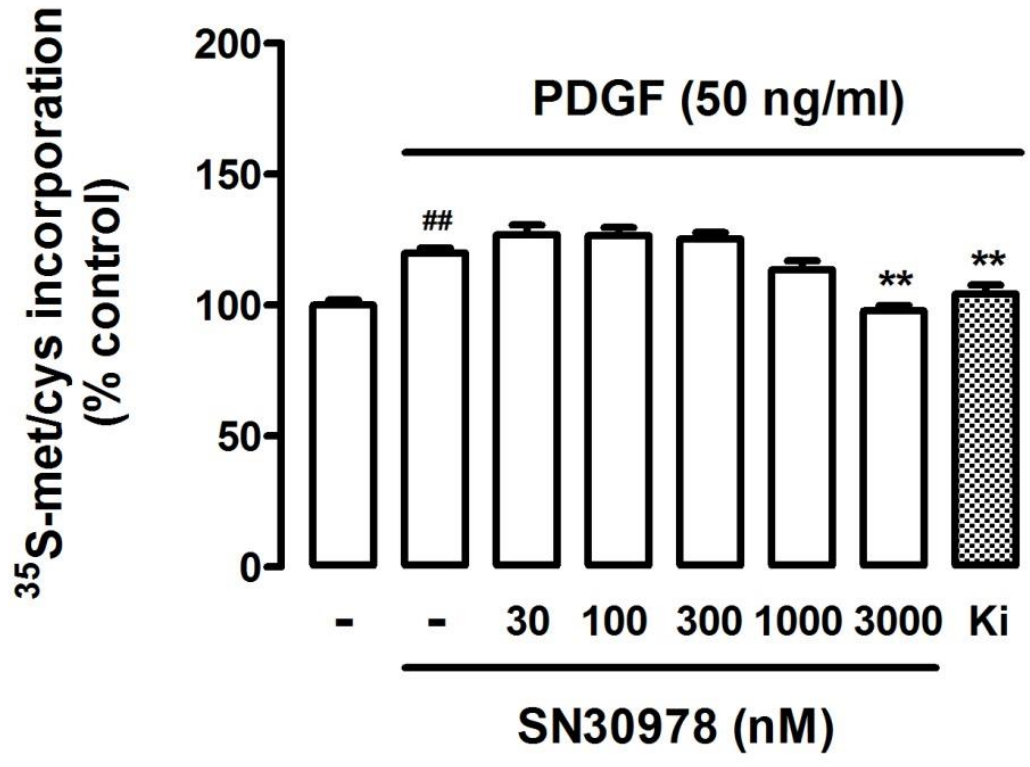


Figure 5

A

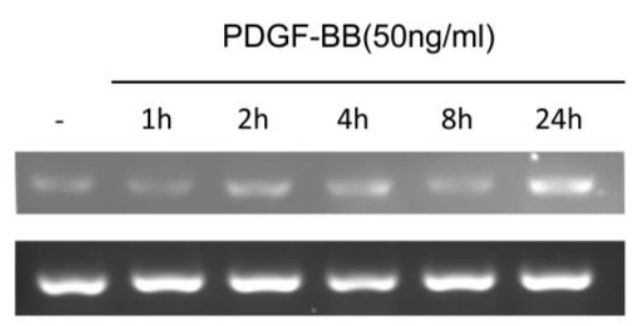

B
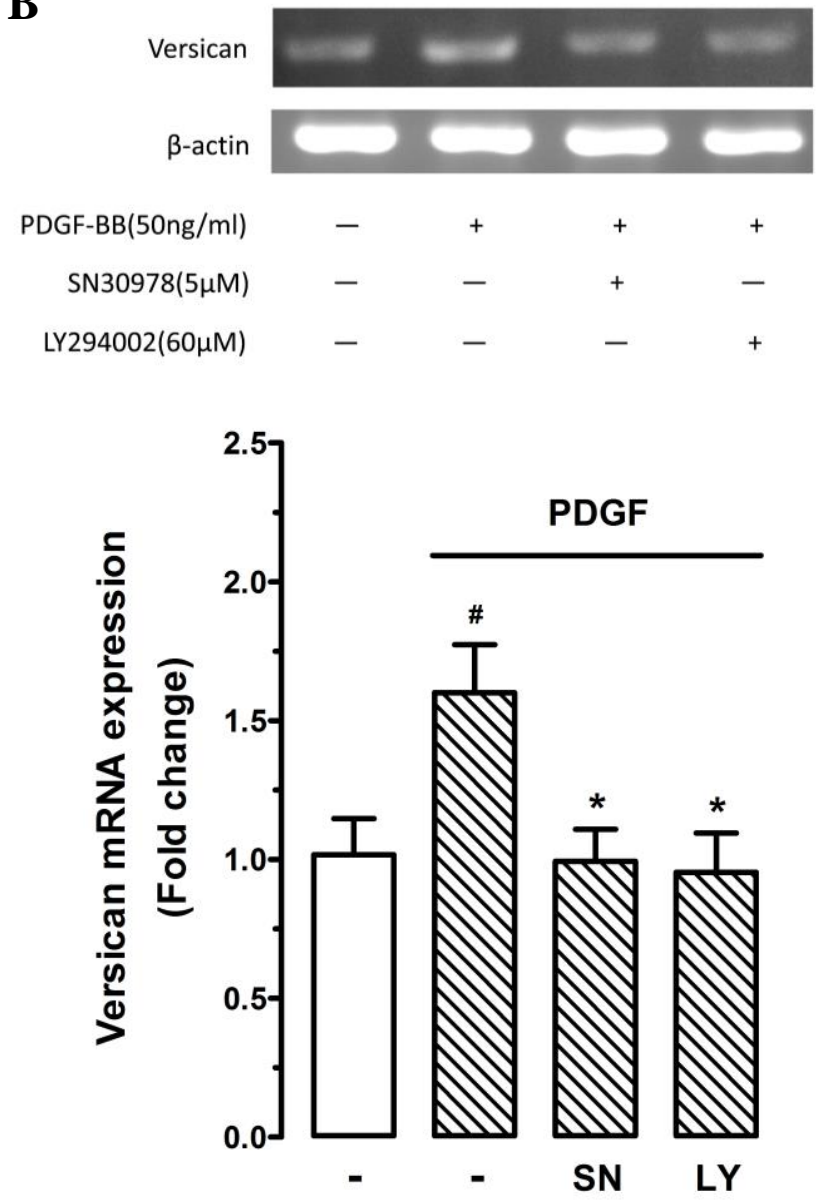


\section{REFERENCES}

1. Ross, R., The pathogenesis of atherosclerosis. N Engl J Med, 1986. 314: p. 488-500.

2. Libby, P., Vascular biology of atherosclerosis: overview and state of the art. Am J Cardiol, 2003. 91(3A): p. 3A-6A.

3. Williams, K.J. and I. Tabas, The response-to-retention hypothesis of early atherogenesis. Arterioscler Thromb Vasc Biol, 1995. 15(5): p. 551-61.

4. Little, P.J., N. Osman, and K.D. O'Brien, Hyperelongated biglycan: the surreptitious initiator of atherosclerosis. Current Opinion in Lipidology, 2008. 19: p. 448-454.

5. Fogelstrand, P. and J. Boren, Retention of atherogenic lipoproteins in the artery wall and its role in atherogenesis. Nutr Metab Cardiovasc Dis, 2012. 22(1): p. 1-7.

6. Osman, N., et al., TGF-beta stimulates biglycan core protein synthesis but not glycosaminoglycan chain elongation via Akt phosphorylation in vascular smooth muscle. Growth Factors, 2011. 29(5): p. 203-10.

7. Nakashima, Y., et al., Early human atherosclerosis: accumulation of lipid and proteoglycans in intimal thickenings followed by macrophage infiltration. Arterioscler Thromb Vasc Biol, 2007. 27(5): p. 1159-65.

8. Nakashima, Y., T.N. Wight, and K. Sueishi, Early atherosclerosis in humans: role of diffuse intimal thickening and extracellular matrix proteoglycans. Cardiovasc Res, 2008. 79(1): p. 14-23.

9. Wight, T.N., Cell biology of arterial proteoglycans. Arteriosclerosis, 1989. 9(1): p. 1-20.

10. Camejo, G., The interaction of lipids and lipoproteins with the intercellular matrix of arterial tissue: its possible role in atherogenesis. Adv Lipid Res, 1982. 19: p. 1-53. 
11. Ballinger, M.L., et al., Regulation of glycosaminoglycan structure and atherogenesis. Cell Mol Life Sci, 2004. 61(11): p. 1296-306.

12. Little, P.J., et al., Proteoglycans synthesized by arterial smooth muscle cells in the presence of transforming growth factor-betal exhibit increased binding to LDLs. Arterioscler Thromb Vasc Biol, 2002. 22(1): p. 55-60.

13. Cardoso, L.E., et al., Platelet-derived growth factor differentially regulates the expression and post-translational modification of versican by arterial smooth muscle cells through distinct protein kinase $\mathrm{C}$ and extracellular signal-regulated kinase pathways. J Biol Chem, 2010. 285(10): p. 6987-95.

14. Ballinger, M.L., et al., Imatinib inhibits vascular smooth muscle proteoglycan synthesis and reduces LDL binding in vitro and aortic lipid deposition in vivo. Journal of Cellular and Molecular Medicine 2010. 14: p. 1408-1418.

15. Ivey, M.E. and P.J. Little, Thrombin regulates vascular smooth muscle cell proteoglycan synthesis via PAR-1 and multiple downstream signalling pathways. Thromb Res, 2008. 123: p. 288-297.

16. Ballinger, M.L., et al., Endothelin-1 activates ETA receptors on human vascular smooth muscle cells to yield proteoglycans with increased binding to LDL. Atherosclerosis, 2009. 205(2): p. 451-7.

17. Anggraeni, V.Y., et al., Correlation of C4ST-1 and ChGn-2 expression with chondroitin sulfate chain elongation in atherosclerosis. Biochem Biophys Res Commun, 2011. 406(1): p. 36-41. 
18. Antonio, L., et al., Glucuronidation of catechols by human hepatic, gastric, and intestinal microsomal UDP-glucuronosyltransferases (UGT) and recombinant UGT1A6, UGT1A9, and UGT2B7. Arch Biochem Biophys, 2003. 411(2): p. 251-61.

19. Burch, M.L., et al., Thrombin stimulation of proteoglycan synthesis in vascular smooth muscle is mediated by protease-activated receptor-1 transactivation of the transforming growth factor beta type I receptor. J Biol Chem, 2010. 285(35): p. 26798-805.

20. Alessi, D.R., et al., Mechanism of activation of protein kinase B by insulin and IGF-1. EMBO J, 1996. 15(23): p. 6541-51.

21. DeFeo-Jones, D., et al., Tumor cell sensitization to apoptotic stimuli by selective inhibition of specific Akt/PKB family members. Mol Cancer Ther, 2005. 4(2): p. 271-9.

22. Neylon, C.B., et al., Intracellular $\mathrm{pH}$ in human arterial smooth muscle. Regulation by $\mathrm{Na}+/ \mathrm{H}+$ exchange and a novel 5-(N-ethyl-N-isopropyl)amiloride-sensitive $\mathrm{Na}(+)-$ and HCO3(-)-dependent mechanism. Circ Res, 1990. 67(4): p. 814-25.

23. Tannock, L.R., et al., Glucosamine supplementation accelerates early but not late atherosclerosis in LDL receptor-deficient mice. J Nutr, 2006. 136(11): p. 2856-61.

24. Nigro, J., R.J. Dilley, and P.J. Little, Differential effects of gemfibrozil on migration, proliferation and proteoglycan production in human vascular smooth muscle cells. Atherosclerosis, 2002. 162(1): p. 119-29.

25. Kresse, H., et al., Biosynthesis and interactions of small chondroitin/dermatan sulphate proteoglycans. Eur J Clin Chem Clin Biochem, 1994. 32(4): p. 259-64.

26. Wight, T.N. and V.C. Hascall, Proteoglycans in primate arteries. III. Characterization of the proteoglycans synthesized by arterial smooth muscle cells in culture. J Cell Biol, 1983. 96(1): p. 167-76. 
27. Jarvelainen, H.T., et al., Differential expression of small chondroitin/dermatan sulfate proteoglycans, PG-I/biglycan and PG-II/decorin, by vascular smooth muscle and endothelial cells in culture. J Biol Chem, 1991. 266(34): p. 23274-81.

28. Schonherr, E., M.G. Kinsella, and T.N. Wight, Genistein selectively inhibits plateletderived growth factor- stimulated versican biosynthesis in monkey arterial smooth muscle cells. Arch Biochem Biophys, 1997. 339(2): p. 353-61.

29. Little, P.J., et al., Biosynthesis of natural and hyperelongated chondroitin sulfate glycosaminoglycans: new insights into an elusive process. Open Biochem J, 2008. 2: p. $135-42$.

30. Wight, T.N. and M.J. Merrilees, Proteoglycans in atherosclerosis and restenosis: key roles for versican. Circ Res, 2004. 94(9): p. 1158-67.

31. Osman, N., et al., p38 MAP kinase mediated proteoglycan synthesis as a target for the prevention of atherosclerosis. Cardiovasc Hematol Disord Drug Targets, 2008. 8(4): p. 287-92.

32. Matsuzaki, K., Smad phosphoisoform signaling specificity: the right place at the right time. Carcinogenesis, 2011. 32(11): p. 1578-88.

33. Yu, J.Y., et al., Genistein inhibits rat aortic smooth muscle cell proliferation through the induction of p27kip1. J Pharmacol Sci, 2008. 107(1): p. 90-8.

34. Sallo, F.B., et al., Bruch's membrane changes in transgenic mice overexpressing the human biglycan and apolipoprotein b-100 genes. Exp Eye Res, 2009. 89(2): p. 178-86.

35. Wight, T.N., Proteoglycans in pathological conditions: atherosclerosis. Fed Proc, 1985. 44(2): p. 381-5. 